\title{
Group Assignments: Perception of Undergraduate Nursing Students
}

\author{
Rabia S. Allari \\ Assistant Professor, College of Nursing, Al-Ahliyya Amman University, Jordan
}

\begin{abstract}
Group assignments introduce the students to be effectively work in teams. Students demonstrate their knowledge while learning to appreciate the perspective of others. The aim of this study is to explore the nursing students' perception of group assignments It is descriptive correlational study using self -administered questionnaire consist of 14 items assessed the perception of group assignment. The sample size was 230 nursing student from colleges of nursing in governmental and private universities in Jordan. The overall mean of students' perception was 3.63 which is neutral. There is no relationship between student perception of group assignments and the academic year as the $p$ value $=(0.699)$ greater than 0.05 . In conclusion, this study serves nursing programs in identifying the specific factors that adds difficulties to the students' abilities to work in teams so as to build their competencies that will serve them in their future career because team work considered as a vital nursing care delivery system in many facilities.
\end{abstract}

Keywords: Group assignment, Nursing, Perception, Students, Undergraduate.

\section{Introduction}

Group assignment at educational establishments is now taken into consideration as one of the first-rate procedures for growing student conversation talents and obtaining information. ${ }^{1}$ Therefore, it is the best approaches for developing students' communication skills and acquiring knowledge. Nuuyoma study revealed that interaction of members engaging in group assignments would develop basic skills, like communication and critical thinking. Institutions work seems to provide instructors in a powerful way to interact college students to growth the undertaking of the responsibilities that students benefit revel in of running to offer college students the opportunity for collaborative operating. However, not everything is positive, so it needs to be considered in the context of the program the level, the nature of the evaluation, student characteristics and so on. However, there are many challenges while using these techniques because of the student perception of unfairness and making group work fully effective is challenging. ${ }^{1}$

Collaborative learning, which is often used interchangeably with cooperative learning, group learning, peer learning, learning community, constructive learning, has become a common practice in schools. ${ }^{2}$ Students are divided into small groups to learn knowledge, to explore an assigned topic, or to complete cases, projects and group assignments, to answer a few challenging questions, or to engage in an exchange of ideas, and share some insights with group members. ${ }^{2}$ Collaborative learning is believed to provide a more comfortable and supportive learning environment than solitary work, foster critical thinking skills, develop individual accountability, increase levels of reasoning and positive interdependence, improve problem-solving strategies, internalize knowledge content. ${ }^{3}$ One research indicates that, regardless of subjects, students who work in groups achieve better results and are more satisfied with their learning experiences than those who do not work in collaborative groups. ${ }^{4}$ Other benefits of this collaborative learning include promoting retention rates, transferring knowledge, providing counseling to students with cognitive, physical, social, and emotional problems, and enhancing their intercommunication skills. ${ }^{4}$ It reflects and responds to the needs of workplaces in industries where team building, cooperation and collaboration are highly 80 emphasized. Therefore, the collaborative learning approach prepares students in problem-solving in a collaborative way and provides them with experiences which could be utilized in their future careers. ${ }^{5}$ 
Tani's study found that there were many contributing factors for Asian students' silence in group participation, such as cultural influences, teacher-student relationships, the composition of the group members, and teaching approaches. However, Tani concluded that these factors were minor when compared to another key factor: when students' participation in group work was tied up with assessment. It was the anxiety and lack of understanding of the system of reward and punishment as demonstrated from group assignments that brought about Asian students' silence. ${ }^{6}$

Michele, et al. study revealed that to increase student participation within the gaining knowledge system, a small group studying have grown to be more and more popular in present days' curriculum. One kind of small group learning is team-based learning, which incredibly new instructional approaches in health care training. ${ }^{7}$ Same study validated that teambased learning is a powerful coaching strategy for huge groups of students. ${ }^{7}$ A key detecting from Michele, et al. study is that, contrary to tutors' perception that students overwhelmingly dislike group assignments given, simply over half of the respondents indicated that they prefer group assignments. Different key findings consist of: most of the people of the respondents feel that they could examine extra by doing organization work, specifically in phrases of the development of team work and verbal exchange competencies. ${ }^{7}$ An extensive sort of communication techniques have been worried for operating on institution assignments, and additionally for person assignments while looking for input and guide from peers. This suggests that the college need to additionally explore and facilitate using these structures. To inspire truthful contribution and enhance the group performance, college students have evolved some of strategies: inspire participation, have organization meetings, use peer strength, share ideas, percentage statistics, proportion workload, and set deadlines. 7 College students do see each advantages and downsides of group paintings. At the same time as the most important blessings often noted are: use peer electricity, percentage workload, extra enter, and expand. ${ }^{7}$

Interpersonal and crew work competencies, learn from peers, and boom self-assurance, the biggest drawbacks are: uneven contribution, terrible commitment, bad time control, and low capacity and contribution. ${ }^{8}$ It is acknowledged that the survey become carried out among students of one university most effective and it may have had biased consequences. But, as students generally have common traits it's far believed that the findings from this observe must be applicable to students' agencies of other training establishments. In addition paintings could cover greater targeted comparison among the perceptions of undergraduate and postgraduate college students. ${ }^{8}$

Likewise, Lázaro, et al. study revealed that team work creates surroundings in which college students have the possibility to develop social skills which include the ability to clarify and mediate differences and construct new understandings and to learn themselves with the aid of interacting with others, all vital sides of forming value Systems. ${ }^{9}$ Many investigations concluded that team work contributes to encouraging interest inside the topic, facilitating resourcefulness and interdependence in learning, and developing skills together with problem identity and evaluation, the exploration of solutions, teamwork, interpersonal communication and challenge management. ${ }^{10,11}$ Moreover, others argued that group work complements motivation, depth of thought processing and degree of success when compared to person paintings. ${ }^{11,12}$

The benefits to students of group work have been demonstrated both in general and in specific contexts. For example, Mello identifies major benefits of group work: (1) students can gain an insight into group dynamics; (2) 'they can tackle a more comprehensive assignments; (3) 'interpersonal skills can be developed; (4) students are more exposed to others points of view'; and (5) be more prepared for the commercial world. ${ }^{13}$ Group work has the potential significantly to improve student engagement, performance, scores and retention, Gibbs clarify that in his review of many literature that groups create better work than do individuals. ${ }^{14}$ But this performance of the group also depend on the number of group member, teacher experience in setting the tasks, students' motivation, and evaluation mechanisms of the group work. ${ }^{14}$ On the other hand group assignment can have negative impact on students' performance related to many reasons according to many literatures. ${ }^{14}$ If the student will create their own group members they will chose based on friendship and common interest. This will end up leading to off- assignment behavior. Also, if allow student pick them self they will chose them selfin a similar level and knowledge and will end up with a result similar to others submitted in class previous to the group activity. One of the goals for group assignment is to raise student thinking and to challenge them. If the outcome is a product similar to what has previously 
been established, there is in fact no increase in achievement. ${ }^{15}$ Group assignment is when small group of students work together to maximize their own and each other's learning. ${ }^{16}$ They point out that individual accountability may be completed where groups are kept to a small number. On the other hand, if groups are large, individual effort can be less. ${ }^{16}$ Also gender effects on student performance with group work, but most of these effects are inconsistent across different studies according to Gibbs with the exception that female students on average more than male students performance. ${ }^{14}$

Group assignment can be hard work emotionally and intellectually. Sometime students want to have time, ability and motivation to work via the levels of forming, norming, storming and performing, on which group work gives rise, faced with difficult group dynamics caused by conflicting personalities, a group may also never attain the stage of efficaciously performing a task through a unified effort. ${ }^{14}$ Due to the character of working in teams, team participants can sometimes discover that they're now not working successfully, which negatively impacts on their grades, development, and their ability to be successful. ${ }^{15}$

Worldwide there are many studies discussed the issue of group work and group assessment as well. However, there have been limited studies that investigate the group assignment design. ${ }^{14}$ Even more, there is no study done in Jordan discussing the perception of nursing students regarding group assignments. It is hoped that the outcomes of this study can contribute to increase body of knowledge regarding the issue. In addition the results of this study will help nursing colleges and programs to improve the quality of higher education to be congruent with contemporary teaching and assessment strategies. Regarding the students, this study results can be helpful in recognizing the specific factors that add difficulties to the students' abilities to work in teams so as to build their competencies that will serve them in the future career because team work considered as a vital nursing care delivery system in many facilities. And the beneficiaries of this research study are measuring students' perception with group assignment that will help to solve student problem with it and to know the challenges facing the students toward group assignments

This study will provide analyses for the findings from questionnaire survey of students' perceptions of group assignments at college of nursing in governmental and private universities in Jordan at undergraduate levels.
The aim of this study is to raise practical issues that faculties and instructors need to consider in designing and carrying out group assessment with a view to overcoming the drawbacks, and amplifying the benefits, of such work, and to improve students' engagement and performance in these activities.

\section{Specifically, this study will answer the following} questions:

1. What is the profile of the nursing students in terms of?

\subsection{Age \\ 1.2. Academic year \\ 1.3. Gender}

2. What is the students' perception of group assignment?

3. Is there a significant correlation between the academic year and students' perception?

\section{Materials and Method}

Research Design: The research design was descriptive correlational to get a picture of current thoughts, feelings, or behaviors in a given group of people. ${ }^{17}$

Setting and Sample: This study was conducted in Governmental and private universities colleges of nursing in Jordan. The sample size of (200) participants was estimated for this study using $G$ power analysis computer program developed by Faul, et al., with a medium effect size 0.15 , power of 0.8 , and $\alpha$ (the risk of Type I error) at $0.05 .^{18}$ The sampling method was convenient snowballing sampling, the inclusion criteria of the target sample was nursing students who is currently registered in the program from first to fourth year.

Research Instruments: Nursing students' perception of group assignment questionnaire developed by Daba, Ejersa and Aliyi was utilized. ${ }^{19}$ It consists of 2 sections. First section asked the students about demographic characteristics, which are age, gender and academic year. The second part consists of 14 items to assess the students' perception about group assignments, 6 items which present advantages of group assignment that accordingly reflect a positive perception and 8 disadvantages that reflect negative perception. It is 5 point Likert scale; started from 1 strongly agree, to 5 strongly disagree. The tool was translated into Arabic 
to avoid misunderstanding by the students (Table 1). Then, the tool was given to panel of experts of academic member who assured face validity and the content is fit the study purpose and culturally suitable. After that reliability of the tool was tested by pilot study. The reliability Chronbach alpha was (0.89).

Data Gathering Procedure: The Questionnaire was electronic self-administered distributed to the students who were recruited through groups on Whatsapp, Face book and through snowballing the students recruit their friends. The data was collected in the period between Marchs to May/2020.

Ethical Considerations: The IRB approval was obtained from university where the researchers work in code number of the permission (12598). In the beginning of the electronic questionnaire the purpose of the study, the risk and benefit of voluntarily participating in the study were mentioned. Participants were reassured of confidentiality and anonymity. The participants had the right to withdraw from the study at any time they want without any consequences.

Statistical Analysis: Data were analyzed using SPSS (version 22). The significance level was set at .05. A number of data analysis procedures were used including means, standard deviations, and frequencies. Pearson's correlation coefficient was the statistical tool selected to assess the relation between student perception of group assignment and the age, gender, and academic year.

\section{Results and Discussion}

The questionnaire was distributed to 250 students to get the intended sample of 200 , the response rate was high $(\mathrm{n}=230,92 \%)$. The average age of participants is $20(\mathrm{SD}=3.8)$. Most of the sample age is ranged between 20 and 24 years old. Of the students, $40.1 \%(n=92)$ were males, while 59.9\% (138) were females. Almost equal responses were received from student in different academic year including (about 57 to $24.7 \%$ per year), and $49.7 \%(n=114)$ were enrolled in private universities compared to 50.3 (116) in governmental universities.

Data in Table (1) showed the frequencies and percentages of students' perception on the group assignments for highest and lowest ranked individual items. The overall students' perception to group assignment was with a mean of 3.54 out of 5 which is considered as neutral perception regarding group assignment in relation to advantages with a mean of 3.5 and disadvantages of group assignment with a mean of 3.51. The highest positive response of group assignment was for item "It gives me a chance to share ideas with others". The highest negative response was for "Some members do not participate".

The item (It gives me a chance to share ideas with others) took the greatest positive mean response, this may be due to the chance of sharing opinions and ideas between students when they are not under the supervision of the instructor and have their privacy in the storming phase of group work, accordingly they are not expected the instructor to give comments or evaluate their ideas. Also, religion and culture encourage people to work collaboratively, and sharing ideas, everyone is improving scientifically at the same time which then allows them all to reach higher levels of expertise even faster, in addition, by expressing opinions new thoughts and ideas that have never been offered before may develop. The more minds that come together and from all different backgrounds, the better they are able to come up with new and unexpected outcomes. When sharing happens, everyone is able to boost productivity at a faster pace. This result is similar to Bentley, \& Warwick who supported that shared workload and ideas, leads to improve grades. ${ }^{8}$ On the other hand, the highest negative item is (some members do not participate) this result may be due to poor back ground knowledge and lack of skills among some group members, also, some members have lack of interest to accept the responsibility for their learning,and lack of social relationship between some students may effects the participation. Also, some students have low self-esteem which may result in avoidance of interaction and communication. Also that, some members depends on other members who work better. This result is similar to Daba, Ejersa and Aliyi. ${ }^{19}$

Of the total respondents 87 students reported their strongly agreement that it is difficult to get together outside the class and this may be due to lack of time because university libraries close at maximum 07:00 $\mathrm{pm}$ that may not give the students the chance to meet after school hours to work on assignments in quite suitable place. Also, some students' study schedules are loaded that will prevent the students from meeting in the university campus to work on assignments. And in many cultures especially in the Middle East there are many social barriers related to meeting after school hours particularly if the students in the same group are from different genders, traffic and lack of suitable places 
for academic meetings. This result is similar to the result of Feichtner and Davis. ${ }^{20}$

First lowest mean item is when (Group members do not respect my opinion) which is negative item but this reflect a positive perception clarify that the students respect each other's even if they not agreed in ideas, Also this result may be due cultural effect which encourages people to respect each other regardless their age, nationalities, religion and race. The second lowest mean item is (I prefer group work than other types of assignments), many students disagreed with this item because there is a lot of evaluation tools that are more equitable and doesn't take much time. Also, some students don't prefer group assignments because of their independent personalities witch make them tend more to work by their own, additionally, some students learn more from individual evaluation tools. ${ }^{21}$ The 3 rd lowest item is (It adds burden work on me), Although this item is a disadvantage of group assignment but not many students agreed with it which is considered as a positive perception about group assignments, and this is because they divide the assignment between them equally. Also, usually professors put deadlines for the submission so they feel obligated to finish the work. Researches identify the benefit for academics and instructors in setting group work assignments in that these can significantly reduce workload. ${ }^{19,21}$

Table 1: Descriptive results of highest and lowest ranked three items of students' perception of group assignments $(\mathrm{N}=\mathbf{2 3 0})$

\begin{tabular}{|c|c|c|c|c|c|c|c|c|c|c|}
\hline \multicolumn{4}{|c|}{ Items } & $\begin{array}{l}\text { Strongly } \\
\text { Disagree }\end{array}$ & Disagree & $\begin{array}{l}\text { Not } \\
\text { sure }\end{array}$ & Agree & $\begin{array}{c}\text { Strongly } \\
\text { Agree }\end{array}$ & Mean & $\begin{array}{c}\text { Std. } \\
\text { Deviation }\end{array}$ \\
\hline \multirow{2}{*}{1} & \multirow{2}{*}{$\begin{array}{l}\text { It gives me a chance to } \\
\text { share ideas with others }\end{array}$} & \multirow{6}{*}{$\begin{array}{l}\text { Positive } \\
\text { perception } \\
\text { (advantages) }\end{array}$} & $\mathrm{N}$ & 7 & 9 & 27 & 92 & 95 & \multirow{2}{*}{4.13} & \multirow{2}{*}{.974} \\
\hline & & & $\%$ & $3.0 \%$ & $3.9 \%$ & $11.7 \%$ & $40.0 \%$ & $41.3 \%$ & & \\
\hline \multirow{2}{*}{2} & \multirow{2}{*}{$\begin{array}{l}\text { It motivates me to } \\
\text { learn from work }\end{array}$} & & $\mathrm{N}$ & 21 & 21 & 47 & 86 & 55 & \multirow{2}{*}{3.58} & \multirow[t]{2}{*}{1.208} \\
\hline & & & $\%$ & $9.1 \%$ & $9.1 \%$ & $20.4 \%$ & $37.4 \%$ & $23.9 \%$ & & \\
\hline \multirow[b]{2}{*}{3} & \multirow{2}{*}{$\begin{array}{l}\text { I learn better from } \\
\text { group interaction than } \\
\text { lecture }\end{array}$} & & $\mathrm{N}$ & 18 & 28 & 48 & 74 & 62 & \multirow{2}{*}{3.58} & \multirow[b]{2}{*}{1.226} \\
\hline & & & $\%$ & $7.8 \%$ & $12.2 \%$ & $20.9 \%$ & $32.2 \%$ & $27.0 \%$ & & \\
\hline \multicolumn{3}{|c|}{ Total mean } & & & & & & & 3.5 & 1.21 \\
\hline \multirow{2}{*}{1} & \multirow{2}{*}{$\begin{array}{l}\text { Some members do not } \\
\text { participate }\end{array}$} & \multirow{6}{*}{$\begin{array}{l}\text { Negative } \\
\text { perception } \\
\text { (disadvantages) }\end{array}$} & $\mathrm{N}$ & 7 & 14 & 38 & 73 & 98 & \multirow{2}{*}{4.05} & \multirow[t]{2}{*}{1.054} \\
\hline & & & $\%$ & $3.0 \%$ & $6.1 \%$ & $16.5 \%$ & $31.7 \%$ & $42.6 \%$ & & \\
\hline \multirow{2}{*}{2} & \multirow{2}{*}{$\begin{array}{l}\text { Group members do not } \\
\text { respect my opinion }\end{array}$} & & $\mathrm{N}$ & 37 & 64 & 66 & 29 & 34 & \multirow{2}{*}{2.82} & \multirow{2}{*}{1.271} \\
\hline & & & $\%$ & $16.1 \%$ & $27.8 \%$ & $28.7 \%$ & $12.6 \%$ & $14.8 \%$ & & \\
\hline \multirow{2}{*}{3} & \multirow{2}{*}{$\begin{array}{l}\text { It is difficult to get together } \\
\text { outside the class }\end{array}$} & & $\mathrm{N}$ & 9 & 28 & 48 & 58 & 87 & \multirow{2}{*}{3.81} & \multirow[t]{2}{*}{1.181} \\
\hline & & & $\%$ & $3.9 \%$ & $12.2 \%$ & $20.9 \%$ & $25.2 \%$ & $37.8 \%$ & & \\
\hline \multicolumn{3}{|c|}{ Total mean } & & & & & & & 3.51 & 1.41 \\
\hline $\mathrm{N}$ & 230 & & & Overa & 1 Average & & \multicolumn{4}{|c|}{3.54} \\
\hline
\end{tabular}

Table (2) showed that there is no correlation between student perceptions and the academic year as the $\mathrm{p}$ value $=(0.668)$ greater than 0.05 . So the hypothesis is rejected.

Table 2: Correlation between students perception and academic year $(\mathbf{n}=\mathbf{2 3 0})$

\begin{tabular}{|l|l|c|c|}
\hline \multicolumn{2}{|c|}{} & Students' perception & Avg. \\
\hline \multirow{4}{*}{ Academic year } & Pearson Correlation & 1 & -.028 \\
\cline { 2 - 4 } & Sig. (2-tailed) & & .668 \\
\cline { 2 - 4 } & N & 230 & 230 \\
\hline
\end{tabular}


This result is compatible with Daba,Ejersa and Aliyiand contradicted with Bentley \& Warwick studies. ${ }^{8,19}$ The result may due to students' engagement in group assignment since they were in the elementary, middle and high school so the level of study is not an affecting factor. Besides that, students have past experience in group assignments at university because it is mandatory since first academic year. Also, Middle East culture and all religions give privileges for teamwork so it is programmed since childhood that teamwork is important and promotes individuals' interdependency as a member in the society.

Since the results of this study suggest that group work is satisfying somewhat to students, we recommend encouraging students from early academic year to participate in group work. Get instructor inputs and clear instructions prior to and during the group assignment, and evaluated the team in a more fair and straightforward way. Establishing training courses to qualify students on how to form groups and deal with group members, also training courses for self-promotion, self-esteem and improving good communication.

\section{Conclusion}

The study aimed to assess students' perception of group assignments and investigate the correlation between their perception and academic year. The general mean result was neutral perception regarding group assignments. Students liked group assignments most because it gives them a chance to share ideas with others and didn't like it most because some members do not participate in the work. Therefore, group assignment is a powerful method in improving student's skills that are relevant to both group and individual work. Also it reinforce skills they need in the professional world such as solving problems, share diverse perspectives, pool knowledge and skills and developing their self-esteem.

Conflict of Interest: The author declares no conflicts of interest.

Source of Funding: This research received no specific grant from any funding agency, commercial entity, or not-for-profit organization.

\section{References}

1. Nuuyoma V. The Group-based Assessment Approach in Nursing Education: The Perspective of Nursing Students on Group-based Assessment
Process at a Namibian University. International Journal of Higher Education. 2017. 6(30): 91-98. URL: https://doi.org/10.5430/ijhe.v6n3p91

2. Zhang J, Cui Q. Collaborative Learning in Higher Nursing Education: A Systematic Review. J Prof Nurs.2018. 34(5): 378-388. doi:10.1016/j. profnurs.2018.07.007.

3. Chung M. "An Overview of Collaborative Work: The Student Experience" Nursing Theses and Capstone Projects. 2012. 108. https:// digitalcommons.gardner-webb.edu/nursing etd $/ 108$

4. Jackson D, Hickman L, Power T, Disler R. Small group learning: Graduate health students' views of challenges and benefits. Contemporary Nurse.2014. 48(1): 117-128.

5. Lee C, Ahonen K, Navarette E, Frisch K. Successful student group projects: Perspectives and strategies. Teaching and learning in nursing. 2015. 10: 186191. http://dx.doi.org/10.1016/j.teln.2015.08.001 1557-3087/

6. Tani M. Quiet, but only in class: reviewing the inclass participation of Asian students. Australian Defense Force Academy, University of New South Wales. HERDSA Conf. 2005. 5: 2005-2007.

7. Michel N, Cater J, \& Varela O. Active versus passive teaching styles: An empirical study of student learning outcomes. Human Resource Development Quarterly. 2009. 20: 397-418. 10.1002/hrdq.20025.

8. Bentley Y \& Warwick S. Students' experience and perceptions of group assignments (Unpublished master's thesis). 2013. University of Bedfordshire, Luton, Bedfordshire. Retrieved from https://www. heacademy.ac.uk/system/files/gen_176_0.pdf

9. Lázaro S, Barco B, CastañoEdel-Río M-I, and Gallego D. Cooperative Team Learning and the Development of Social Skills in Higher Education: The Variables Involved. Front. Psychol. 2018. 9:1536. doi: 10.3389/fpsyg.2018.01536

10. Payne K, Elizabeth T, Donald S, Melvina S. Improving Group Work: Voices of Students. Education. 2006. 126 (3): 441-448.

11. LaBeouf J, Griffith J, \& Roberts D. Faculty and Student Issues with Group Work: What is Problematic with College Group Assignments and Why? Journal of Education and Human Development. 2018. 5(1): 13-23. URL: http:// dx.doi.org/10.15640/jehd.v5n1a2 
12. Saleh TA. Statistical Analysis of Cooperative Strategy Compared with Individualistic Strategy: An Application Study. The Journal of Effective Teaching. 2011. 11(1): 19-27.

13. Mello J A. Improving Individual Member AccountabilityinSmallWorkGroupSettings. Journal of Management Education. 1993. 17: 253-259. http://dx.doi.org/10.1177/105256299301700210

14. Gibbs G. The assessment of group work: lessons from the literature, Assessment Standards Knowledge exchange, Brooks University, UK. 2009.

15. B. Assigning Individual Roles and its Effect on the Cooperative Learning Setting (Master's thesis, St. John Fisher College). Fisher Digital. Publications. 2010. https://fisherpub.sjfc.edu/cgi/viewcontent. cgi? article $=1098 \&$ context $=$ mathcs_etd_masters

16. Stangor C. Psychologists Use Descriptive, Correlational, and Experimental Research Designs to Understand Behavior. In Introduction to Psychology. 2011. Retrieved from Introduction to Psychology http://open.lib.umn.edu/intropsyc/ chapter/2-2-psychologists-use-descriptivecorrelational-and-experimental-research-designsto-understand-behavior/
17. Faul F, Erdfelder E, Lang A, et al. G*Power 3: A flexible statistical power analysis program for the social, behavioral, and biomedical sciences. Behavior Research Method. 2007. 39: 175-191 . https://doi.org/10.3758/BF03193146

18. Daba T M, Ejersa S J, \& Aliyi S. Student perception on group work and group assignments in classroom teaching: The case of Bule Hora university second year biology students, South Ethiopia: An action research. Educational Research and Reviews. 2017. 12(17): 860-866.

19. Feichtner S, and Davis E. Republication of "Why some groups fail: A survey of students' experiences with learning groups". 2016. [Online] jme.sagepub. com. Available at: http://journals.sagepub.com/doi/ pdf/\%2010.1177/1052562915619639

20. Weimer M. What Happens When Students Study Together? Faculty Focus. 2016. http://www. facultyfocus.com/articles/teachingprofessor-blog/ happens-students-study-together/

21. JISC. E-Assessment: An overview of JISC activities. JISC funded e-assessment developments. 2008. http://www.jisc.ac.uk/publications/ briefingpapers/2008/b peassessoverviewv2.aspx 